\title{
Sketching while Narrating as a Tool to Detect Deceit
}

\author{
Aldert Vrij \\ Samantha Mann \\ Sharon Leal \\ Ronald P. Fisher \\ Haneen Deeb
}

\begin{abstract}
Author Note
Samantha Mann, Aldert Vrij, Sharon Leal and Haneen Deeb, Department of Psychology, University of Portsmouth; Ronald P. Fisher, Department of Psychology, Florida International University.

Correspondence concerning this article should be addressed to Aldert Vrij, Department of Psychology, University of Portsmouth, King Henry Building, King Henry 1 Street, PO1 2DY, Hants, United Kingdom. Email: aldert.vrij@port.ac.uk
\end{abstract}

The authors have no conflict of interest to declare 


\begin{abstract}
In none of the deception studies that used drawings to date, was the effect of sketching on both speech content and drawing content examined, making it unclear what the full potential is of the use of drawings as a lie detection tool. A total of 122 truth tellers and liars took part in the study who did or did not sketch while narrating their allegedly experienced event. We formulated hypotheses about the total amount of information and number of complications reported and about various features of the drawings. Participants in the Sketch-present condition provided more information than participants in the Sketch-absent condition, and truth tellers reported more details than liars, but only in the Sketch-present condition. In contrast to previous research, no Veracity differences occurred regarding the content of the drawings, perhaps because sketching was introduced as a tool that facilitated verbal recall and not as a stand-alone tool.
\end{abstract}

Keywords: Information-gathering, deception, drawings 


\section{Sketching while Narrating as a Tool to Detect Deceit}

Since cues to deceit are typically faint and unreliable (DePaulo et al., 2003; DePaulo \& Morris, 2004), researchers have started to design interview tools aimed at eliciting or enhancing such cues (Vrij \& Granhag, 2012). One such interview tool is the use of drawings. In their overview of deception studies that used drawings, Mac Giolla, Granhag and Vernham (2017) reported that differences between truth tellers' and liars' drawings frequently occur. They concluded that the use of drawings has potential to detect detection. In all studies summarized by Mac Giolla et al. (2017), sketching occurred in isolation of speech. That is, participants were never asked to narrate and sketch at the same time. In a later study (Vrij et al., 2018), participants were asked to narrate while they sketched, and differences between truth tellers and liars in speech content emerged; however, in that study the content of the drawings was not analysed. Therefore, in none of the deception studies that used drawings to date, was the effect of sketching on both speech content and drawing content examined, making it unclear what the full potential is of the use of drawings as a lie detection tool. We examined the contents of both speech and drawings in the present experiment.

\section{Sketching and the information provided}

Sketching while narrating facilitates recall in truth telling adults (Dando, Wilcock, \& Milne, 2009; Leins, Fisher, Pludwinsky, Robertson, \& Mueller, 2014; Mattison, Dando, \& Omerod, 2015) as well as in truth telling children (Barlow, Jolley, \& Hallam, 2010; Butler, Gross; \& Hayne, 1995; Wesson \& Salmon, 2001). Sketching while narrating is an important element of the Cognitive Interview (Fisher \& Geiselman, 1992). Vrij et al. (2018a, 2019) provided four reasons why sketching while narrating facilitates recall: (i) it mentally reinstates the context of the interviewee's experience and context reinstatement facilitates recall; (ii) it is a visual output and therefore compatible with visually experienced events. Compatible output formats facilitate recall; (iii) it is a time-consuming activity which slows down the 
thinking process. It thus gives truth tellers good opportunity to search their memory which facilitates recall; (iv) it automatically leads to providing spatial information because someone must situate each person or object somewhere in the location s/he sketches. In a verbal response, interviewees do not always spontaneously report where persons and objects were exactly located. Another possible reason is that drawing facilitates retrieval because drawing one aspect of an event may cue retrieval of other aspects of that event (Barlow, Jolley, \& Hallam, 2010; Butler, Gross; \& Hayne, 1995; Wesson \& Salmon, 2001).

\section{Veracity and the information provided}

Truth tellers typically report more details than liars (Amado, Arce, Fariña, \& Vilarino, 2016). Liars may be unable to report many details that sound plausible (Köhnken, 2004). Liars may also be unwilling to report many details out of fear (i) that such details give possible leads to investigators that they are lying (Nahari, Vrij, \& Fisher, 2014) or (ii) that they cannot remember their own fabrications consistently when they are asked to recall their story again (Vrij, 2008).

Researchers recently started to examine specific types of detail: Complications, common knowledge details and self-handicapping strategies. A complication is an occurrence that affects the story-teller and makes a situation more difficult (e.g., "Initially we could not see each other, each of us was waiting at a different entrance") (Vrij et al., 2020). Selfhandicapping strategies refer to justifications as to why someone is not able to provide information ("I can't remember the details; it happened a while ago") (Vrij, Leal, Jupe, \& Harvey, 2018). Common knowledge details refer to strongly invoked stereotypical information about events (e.g., "We went to the Louvre Museum in Paris where we saw the Mona Lisa") (Vrij, Leal, Jupe, \& Harvey, 2018). Truth tellers typically report more complications than liars, whereas liars typically report more common knowledge details and self-handicapping strategies than truth tellers (Leal, Vrij, Deeb, \& Kamermans, 2019; Vrij et 
al., 2017, 2018a, b, 2019, 2020). The research to date also showed that complications is the most diagnostic cue out of these three variables. Our pre-registered hypotheses therefore focused on this variable only, but the other two variables will be explored. Truth tellers are thought to report more complications than liars, due to liar's tendency to keep their stories simple (Hartwig, Granhag, \& Strömwall, 2007). In all the studies in which complications, common knowledge details and self-handicapping strategies were examined, participants reported events of a relatively long duration (e.g. a trip away) that happened some time ago (e.g. a few months). In the current experiment, the event the participants reported was much shorter (around 20 minutes) and happened just before the interview took place. The short duration of the event could have an effect on complications because they are probably more likely to occur when the to-be-recalled event is of a longer duration (Vrij et al., 2018b).

Liars are thought to report more self-handicapping strategies than truth tellers, because they are inclined to keep stories simple, but are -at the same time- concerned that admitting lack of memory appears suspicious (Ruby \& Brigham, 1998). A solution is to provide a justification for the inability to provide information. However, such justifications may be more difficult to create when someone recalls an event that happened a short while ago. Liars may therefore refrain from using self-handicapping strategies in such situations. Liars are thought to report more common knowledge details than truth tellers, because liars lack personal experiences to add to their descriptions of events (Sporer, 2016). However, the event participants were asked to report in the present experiment was out of the ordinary and people are unlikely to have stereotypical knowledge about extraordinary events. We therefore thought common knowledge details unlikely to arise in the current experiment.

\section{Sketching while narrating: A differential effect on truth tellers and liars}

Since liars are typically unable or unwilling to report many details, sketching should not have the same positive effect on facilitating recall as it has on truth tellers. As a result 
sketching should enhance the difference in reporting details between truth tellers and liars. This was indeed found in Vrij et al. (2018a). In their experiment, truth tellers reported key moments during a trip away they had made, whilst liars pretended to have experienced such key moments. Truth tellers provided more details as well as more complications than liars, but only in the sketch condition. In contrast, using the same deception scenario, Vrij et al. (2019) found no effect of sketching on reporting details or complication. They speculated that the null effects were caused by a specific instruction given to their participants. Before introducing the Sketch manipulation, they asked participants to write down possible key moments they wanted to discuss during the interview. Through this instruction, participants may have committed themselves to what to report prior to the Sketch manipulation, which may have overshadowed the effect of the Sketch manipulation itself. In the present experiment - like in Vrij et al. (2018a) - no such prior instructions were given to participants.

\section{Sketching Features}

We are aware of 11 publications in which drawings were introduced as a tool to detect deceit. They are indicated with a '*' in the Reference list and see Mac Giolla, Granhag and Vernham (2017) for a review of many of these studies. In most of these studies sketching occurred in isolation of speech (participants did not sketch and talk at the same time) and features of the drawings were examined. The review showed that the drawings of truth tellers included more details and were more concrete (e.g. drawings that represent complex scenes, referring to a specific context) than those of liars (Mac Giolla, Granhag, \& Vernham, 2017). This resembles the differences in speech content between truth tellers and liars, discussed in the Veracity section earlier, and could be the result of liars being unable or unwilling to provide as many details as truth tellers. The review also showed that truth tellers included more bystanders in their sketches than liars (Mac Giolla, Granhag, \& Vernham, 2017). A 
possible explanation is that liars fear that witnesses, when contacted, can incriminate them and liars thus prefer not to sketch people who witnessed their actions.

In a study that used a similar scenario as used in the current study, participants were asked to sketch the scenario when they received a package from a fellow agent (Vrij, Leal et al., 2010). Truth tellers, more than liars, included the fellow agent in their sketch Again, this could be the result of liars being unwilling to report witnesses who could incriminate their actions. In the same study, it was also found that truth tellers, more than, liars made their drawings from an over-the-shoulder camera perspective (what they actually could see), whereas liars, more than truth tellers, used a birds-eye overhead camera perspective (what somebody could see from the air). Vrij, Leal et al. (2010) explained this in terms of directness. Verbal deception research has shown that truth tellers use more direct phrases than liars (DePaulo et al., 2003) and a similar distinction between 'direct' and 'indirect' could be made in the drawings. The shoulder-camera perspective is more direct than the birds-eye camera perspective, which removes the participant from the scene. A birds-eye perspective also provides liars with the opportunity to sketch something they know (e.g. the layout of a location) without having to fabricate idiosyncratic details about what happened at that location. We examined whether the same features in drawings that were diagnostic when participants sketched in isolation of speech also occur when participants narrate when they sketch, as in the current experiment. When people sketch without narrating, the drawing becomes a stand-alone (visual) output. When people sketch while narrating, the sketch itself becomes less important and functions as an aid to facilitate verbal recall. Therefore, differences between truth tellers and liars found in stand-alone drawings may not necessarily be generalised to drawings that are made to aid memory recall.

When we ask people to sketch they often reply that their ability to sketch is poor. We examined whether liars would use this as a self-handicapping strategy. After the interview 
was completed, liars and truth tellers were asked to sketch a scenario familiar to them. We asked this of all participants, including those in the Sketch-absent condition. If liars used an 'I cannot draw' self-handicapping strategy during the interview, they are likely to continue this self-handicapping strategy when sketching this familiar scenario. The result would be that the quality of the familiar scenario drawings (e.g. objects and persons being accurately represented) would be worse in the Sketch-present than in the Sketch-absent condition, particularly for liars.

\section{Strategies}

In several studies to date participants were asked to report their strategies to appear convincing during the interview. If differences in strategies between truth tellers and liars emerge, investigators can design interview protocols that exploit such differences. Research to date found differences between truth tellers and liars in verbal strategies to appear convincing. Truth tellers typically employ a 'tell it all' approach and are willing to report all details they can remember (Colwell, Hiscock-Anisman, Memon, Woods, \& Michlik, 2006; Hartwig, Granhag, \& Strömwall, 2007). In contrast, liars typically employ a 'keep it simple' approach (Colwell et al., 2006; Hartwig, Granhag, \& Strömwall, 2007). Presumably, this occurs because liars wish to refrain from providing too many details, and especially details that could incriminate them. The less they say the easier it is for them to remember what they have said so that they do not contradict themselves if asked to describe their experiences again. Another verbal strategy liars employ is staying close to the truth (Leins, Fisher, \& Ross, 2013). In that way liars can report actually experienced idiosyncratic details and -at the same time- may sound convincing.

The nonverbal strategies truth tellers and liars report to appear convincing are more similar to each other than their verbal strategies (Hartwig, Granhag, Strömwall, \& Doering, 2010; Vrij, Mann, Leal, \& Granhag, 2010). Both truth tellers and liars attempt to suppress 
nonverbal cues that they believe may appear dishonest (gaze aversion, making movements, stuttering). They also attempt to convince the interviewer of their honesty, for example, through smiling.

It has not yet been examined how these strategies translate into verbal statements. Of particular interest is the question whether liars who reported to have stayed close to the truth provide more details than liars who have not used such a strategy. This question frequently comes up in our talks with practitioners. We examined this in the current experiment.

\section{Hypotheses}

The following hypotheses were tested:

- Truth tellers will report more details (Hypothesis 1a) and more complications (Hypothesis 1b) than liars

- Narrating while sketching will result in more details (Hypothesis 2a) and more complications (Hypothesis 2b) than narrating without sketching (Sketching main effect, Hypothesis 2), particularly in truth tellers (Veracity x Sketching interaction effect, Hypothesis 3)

- Truth tellers will include more details in their sketches than liars (Hypothesis 4)

- Truth tellers' drawings will be more concrete than liars' drawings (Hypothesis 5)

- Truth tellers will include more witnesses in their sketches than liars (Hypothesis 6)

- Truth tellers, more than liars, will include the fellow agent in their sketches (Hypothesis 7)

- Truth tellers, more than liars, will use a shoulder-camera perspective (Hypothesis 8)

This study and all hypotheses except Hypotheses 4 and 5, were pre-registered at https://osf.io/ph3mu/

\section{Participants}

\section{Method}


A total of 122 University students and staff members (34 males and 88 females) took part in the study ${ }^{1}$. Their average age was $M=26.10$ years $(S D=1.72)$. Participants had responded to an advert entitled "Sketchy Stories: Whose side are you on?" The advert explained that the experiment would involve going on a short mission and being interviewed (which would be audio-recorded). They would be asked to lie or tell the truth about the mission. Participation would take 45-60 minutes for which they would receive $£ 10$, plus entry into a draw for vouchers if they could successfully convince an interviewer.

\section{Experimental conditions}

Participants were allocated randomly to one of the four experimental cells. A total of 60 participants were allocated to the truth condition and 62 to the lie condition; 62 to the Sketching-absent condition and 60 to the Sketching-present condition. Individual cell sizes varied from 30 to 32 .

\section{Procedure}

The procedure was derived from Vrij et al. (2010) and Vrij, Leal, Mann, \& Fisher (2012). On arrival participants met the experimenter who gave them the Participant Information Sheet to read. Participants were then sent on a mission which involved going to a cafeteria within a nearby university building (approximately 7-minute walk), meet an 'agent', exchange a code, receive a package and return. The experimenter read out instructions which explained to the participant where to go, how to identify the agent (s/he would have a distinctive pink and purple flowery laptop bag) and to confirm identification by asking the agent a code question ("Do you have the correct time?") to which the agent should reply the code response ("Sorry my watch stopped at 5am"). After confirming identity of the agent the participant was to take a seat and the agent would give them the package, a tracking device. The participant was then told to return to the experimenter with the device. The experimenter then explained that on their return they would be interviewed by one of two agents, either one 
from their team or from another team and that further instructions regarding that would be given on their return, but depending on which, they may be asked to lie about their mission. She then asked the participant to sign an Informed Consent Form. Participants were offered to take a map and instructions if they wanted them (only two participants asked to take the instructions). As the participant set off, the 'agent' was warned by text that the participant was on the way. Once the participant had collected the device from the agent s/he texted the experimenter to alert her that the participant was on the way back. On their return the participant gave the experimenter the device and received the following instructions depending on which group they had been assigned to:

Truth tellers: "You are now going to be interviewed. The interviewer is on your team. Therefore, tell the interviewer everything that you can remember about your mission in as much detail and as fully as you can. You need to convince the interviewer you are telling the truth to be entered into the draw. Furthermore, if you do not convince the interviewer you will be asked to write a statement about your mission. You may have some time to prepare if you wish"

Liars: "You are now going to be interviewed. The interviewer is not on your team. Therefore, you need to mislead the interviewer about everything to do with the exchange. The interviewer knows you just went out on a mission locally, but you need to lie about the package, the agent you received it from, and the location where you met and received it - so you need to change these details of your mission. However, you need to convince the interviewer you are telling the truth to be entered into the draw. Furthermore, if you do not convince the interviewer you will be asked to write a statement about your mission. You may have some time to prepare if you wish"

Liars generally asked for time to prepare their story. They were then given as much time as they wanted and it typically took them about five minutes to prepare. Truth tellers 
generally did not ask for preparation time. When the participant said they were ready the experimenter gave the participant a brief pre-interview questionnaire. In the pre-interview questionnaire the truth tellers and liars rated their thoroughness of preparation via three items: (1) shallow to (7) thorough; (1) insufficient to (7) sufficient; and (1) poor to (7) good. The answers to the three questions were averaged (Cronbach's alpha $=.83$ ) and the variable is called 'preparation thoroughness'. They were also asked whether they thought they were given enough time to prepare themselves with the following question: 'Do you think the amount of time you were given to prepare was: (1) insufficient to (7) sufficient. This variable is called 'preparation time'. Finally, they were asked how motivated they were to perform well during the interview: (1) not at all motivated to (5) very motivated. After completing the pre-interview questionnaire participants were taken into the interview room and introduced to the interviewer.

\section{The interview.}

The interviewer explained that the interview would be audio-recorded and switched on the recorder. The interviewer started by saying "I will interview you about the mission you just completed. Depending on your answers, we may decide to interview you a second time”. This was followed by the following request: "Please tell me in as much detail as possible everything you did from the moment you left this building to the moment you came back". We label this initial request and answer, Initial Free Recall.

After the interviewee's answer, the interviewer said: "Now please focus on the moment you collected the package. Take a few moments to picture in your mind everything you saw, heard and did at that time." When the interviewee indicated to be ready the interviewer asked: "Now please tell me in as much detail as possible everything you saw, heard and did at that time" (Sketch-absent condition) or "Now please tell me in as much detail as possible everything you saw, heard and did at that time, but while doing this please make a 
sketch including as much information as you can of the exchange. I appreciate that not everyone finds it easy to draw. So remember to talk to me whilst you draw so that I can understand your drawing fully." (Sketch-present condition). If the interviewee stopped talking the interviewer encouraged him/her to keep on talking while sketching. We label this followup request and answer, Follow-up Recall. We introduced this two-Phases interview structure (Initial Free Recall and Follow-up Recall) because it reflects a typical interview setting in which a general question is followed by questions about specific elements discussed in the initial answer (Milne \& Bull, 1999).

After the interview the participant was taken back to the experimenter, who asked when s/he had last sat down and had a meal (e.g. breakfast or lunch that day or dinner the night before). All participants, including those in the Sketch-absent condition, were then asked to draw, in their own time and without talking, where they had eaten that meal. We refer to this drawing as the baseline drawing, whereas the drawing made during the interview is called the exchange drawing. After the participant had completed his/her drawing, s/he was asked to complete a post-interview questionnaire.

\section{Post-interview questionnaire.}

Participants were asked to complete the post-interview questionnaire truthfully. They were asked to indicate the extent to which they told the truth during the interview on an 11 point Likert scale ranging from $0 \%$ to $100 \%$. We further asked participants in the Sketchpresent condition about their experiences. We asked them the following four questions, which they answered on 7-point scales ranging from (1) not at all to (7) very much so: (a) 'Sketching while narrating was easy to do', (b) 'Sketching while narrating was difficult to do', (c) 'Sketching while narrating made it easier for me to think what I wanted to say', (d) 'Sketching while narrating made it more difficult for me to think what I wanted to say'. Questions (b) and (d) were recoded and the four questions were averaged to form the cluster 
labeled "easy to sketch and talk" (Cronbach's alpha $=.83)$. On completion of the postinterview questionnaire, the participant were thanked, fully debriefed and given $£ 10$ for taking part. All participants were told that they had convinced the interviewer and were entered into the draw for the Amazon vouchers.

\section{Coding.}

Detail. The interviews were transcribed and coding occurred from the transcripts. A coder, who was blind to the experimental conditions, first read the transcripts and coded each detail in the interview. A detail is defined as a unit of information about the mission the interviewee allegedly had undertaken. For example, the following sentence has eight details: "I left the building, I went behind this building to the traffic lights, I waited first because they were red" and the following sentence has 13 details: "I went through the main entrance to the $\underline{\text { big foyer, and right by there is a café and there was somebody there with a drink, a female }}$ with short brown hair" Each detail in the interview was coded only once; thus repetitions were not coded. This also applies to repetitions between the answers given in the Initial Free Recall and Follow-up Recall. We distinguished between (i) details reported about taken to and from the location and (ii) details reported about what happened at the location. This distinction is relevant because the Follow-up Recall focused on what happened at the location only. A second coder, who was also blind to the experimental conditions, coded a random sample of 25 transcripts. Inter-rater reliability between the two coders, using the two-way random effects model measuring consistency, was excellent: Details about route taken, Single Measures ICC $=.99$; Total details about what happened at the location, $\mathrm{ICC}=.96$.

Actually, the coders divided the details about what happened at the location in five subcategories. We used the Total details about what happened at the location score (sum of the scores on the five subcategories) in the hypothesis-testing analysis but included these subcategories in an exploratory analysis. The results provide insight into what types of detail 
are mostly elicited through a sketch instruction. For example, since sketching is a visual output someone could expect that it particularly encourages the description of visual details (what the participant saw at the location) rather than details about what they themselves did or thought. These subcategories were (with the ICC in brackets) descriptions of: (i) interior of the location (ICC $=.66$ ); (ii) agent including his/her actions ( $\mathrm{ICC}=.78)$; (iii) what the interviewee thought and did at the location ( $\mathrm{ICC}=.57)$; (iv) verbal exchange with the agent $(\mathrm{ICC}=.78)$; and $(\mathrm{v})$ package received from the agent $(\mathrm{ICC}=.85)$.

One coder, who was blind to the experimental conditions, coded the number of complications and self-handicapping strategies in all transcripts. We decided not to code for common knowledge details, because in an initial scrutiny of the transcripts we did not notice any common knowledge details. Repetitions were not coded. A complication is an occurrence that makes a situation more difficult to report than necessary (Vrij et al., 2018b). Example of complications are (a) "At first I thought it was a cafeteria but then it turned out that it wasn't", (b) "And then I thought I had to sit down so I started to sit down but then the guy just gave me the device" and (c) "And I was smiling because I thought he would smile too but he didn't so I was like, OK, I get it you just do your job”. Self-handicapping strategies refer to explicit or implicit justifications as to why someone is not able to provide information (Vrij et al., 2018b). Examples of self-handicapping strategies are: (a) “I can't tell her age; with females it is very hard to tell their age", (b) "I didn't focus on anything else other than the agent" and (c) "I can't remember much; it all happened quite quickly".

For complications and self-handicapping strategies we could distinguish only between Details about route taken and Details about what happened at the location overall. Not enough complications and self-handicapping strategies occurred at the location to identify subcategories (i.e. Description of agent and actions, Description of verbal exchange, Descriptions of interviewee's thoughts and feelings etc.). 
A second coder, who was also blind to the experimental conditions, coded a random sample of 25 transcripts. Inter-rater reliability between the two coders, using the two-way random effects model measuring consistency, was good for complications (Single Measures, Intraclass correlation coefficient, ICC $=.81$ ) and satisfactory for self-handicapping strategies (Single Measures ICC $=.62$ ).

Drawings Coding. Based on an examination of the drawings produced by participants in the Sketch-present condition, a coding scheme was devised. The coding scheme included four variables which were rated as present or absent: Did the participant include in the drawing: (i) Him/herself; (ii) The agent; (iii) the package; and (iv) any speech details (e.g. speech bubbles). For the him/herself and agent details, where drawings were unclear, the coder also referred to the interview transcripts in the Follow-up Recall to determine whether the participant was indeed drawing him/herself and the agent. In addition, the number of details sketched about (v) the location and (vi) the agent and his/her actions were counted. For the hypothesis-testing analysis we used the total details variable, which is the sum of all variables mentioned above. We also examined the individual categories in an exploratory analysis.

A coder coded all drawings and a second coder coded a random sample of 15 drawings. Both were blind to the Veracity condition. Inter-rater reliability between the two coders, using the two-way random effects model measuring consistency, was excellent for total details (Single Measures, Intraclass correlation coefficient, ICC $=.96$ ). Inter-rater reliability for the details about the location $(\mathrm{ICC}=.83)$ and agent and exchange $(\mathrm{ICC}=.97)$ were also very good. For the four absent/present variables, Kappa's were calculated showing excellent reliability: sketching him/herself, Kappa $=1.00$; sketching agent, Kappa $=1.00$; sketching package, Kappa $=1.00$; sketching speech details, Kappa $=1.00$.

The coder and second coder also coded whether the drawing was sketched from a birds-eye view (layout) or a shoulder-camera view (i.e. as seen) $($ Kappa $=.79)$ and how many 
people other than the agent and participant were sketched $(\mathrm{ICC}=.92)$. Reliability was good for both variables.

The coders also rated the drawing ability displayed in the sketch (e.g. were objects and persons accurately represented) on a 7-point Likert scale from [1] poor to [7] excellent (ICC = .75 ) and the drawing concreteness (drawings that represent complex scenes, referring to a specific context) on a 7-point Likert scale ranging from [1] not at all clear what the sketch depicts to [7] very clear drawing $(\mathrm{ICC}=.84)$. Also for these variables reliability was good.

For the baseline drawing, we asked participants to sketch where they ate their most recent meal. The coder and second coder counted the details about the food, people and location. Reliability was excellent $(\mathrm{ICC}=.99)$. Again the drawing ability displayed in the sketch was rated from [1] very poor to [7] excellent $(\mathrm{ICC}=.56)$; the drawing concreteness was rated from [1] not at all clear what the sketch depicts to [7] very clear (ICC $=.67$ ). Reliability was acceptable for these two variables.

Self-reported Strategies Coding. In the pre-interview questionnaire participants were asked: Have you developed a strategy to be convincing in the interview? If yes, please describe that strategy. In the post-interview questionnaire participants were asked: Did you use a strategy to be convincing in the interview? If yes, please describe that strategy.

Responses to these questions are listed in Appendices 1 and 2 and subsequently clustered into seven strategies, listed in Table 4. For each participant, a strategy was coded as absent or present and each participant could have used more than one strategy. A second coder then coded a random sample of 25 transcripts. Inter-rater reliability between the two coders using Kappas was good: (i) Staying close to the truth, Kappa = .78; (ii) Keeping it simple, Kappa $=.83$; (iii) Give detail, Kappa $=.80$; (iv) Use countermeasure technique, Kappa $=1.00 ;(v)$ Use countermeasures towards interviewer, Kappa $=.84$; (vi) Control nonverbal behaviour: Visual, Kappa $=.88$; Control nonverbal behaviour: Vocal, Kappa $=.78$. 


\section{Results}

\section{Questionnaire Variables}

\section{Preparation thoroughness, preparation time and motivation}

Three 2 (Veracity) X 2 (Sketch) ANOVAs were carried out with preparation thoroughness, preparation time and motivation as dependent variables. None of the main or interaction effects were significant, all $F$ 's $<2.85$, all $p$ 's $>.093$.

Note that preparation thoroughness and preparation time were measured on 7-point Likert scales and motivation on a 5-point Likert scale. The total mean for preparation thoroughness was $M=5.05(S D=1.33)$, suggesting that participants assessed their preparation thoroughness as somewhat good. The total mean for preparation time was $M=$ 5.27 , indicating that participants thought they were given sufficient time to prepare themselves. The total mean for motivation was $M=4.48(S D=0.65)$, which means that participants were very motivated.

\section{Easy to sketch while talking}

A one-way ANOVA with Veracity as factor and Easy to sketch while talking as dependent variable revealed no main effect for Veracity, $F(1,58)=1.96, p=.167, d=0.36(-$ $0.15,0.87)$. The total mean was $M=4.91(S D=1.42)$, suggesting that participants found it relatively easy to sketch.

\section{Percentage of truth telling}

An ANOVA utilizing a 2 (Veracity) X 2 (Sketch) between-subjects design was carried out with percentage of truth telling as dependent variable. A main effect for Veracity occurred $F(1,118)=1006.22, p<.001, d=5.50(4.65,6.19)$, with truth tellers $(M=99.00, S D=3.02$, $95 \%$ CI $[95.68,102.32])$ reported to have been more truthful than liars $(M=24.52, S D=$ $19.05,95 \%$ CI $[21.03,27.57])$. The Sketch main effect was also significant, $F(1,118)=8.76$, $p=.004, d=0.15(-0.21,0.50)$, with those who did not sketch $(M=64.03, S D=37.31,95 \%$ 
CI $[61.86,68.41])$ reporting to have been more truthful than those who sketched $(M=58.17$, $S D=42.37,95 \%$ CI $[54.84,61.49])$. The Veracity X Sketch interaction effect was also significant, $F(1,118)=7.16, p=.009, \eta_{p}{ }^{2}=.01$. Simple effect tests showed no significant difference between the no-sketch and sketch conditions for truth tellers, $F(1,58)=0.73, p=$ $.398, d=0.22(-0.29,0.72)$, whereas the difference between the no-sketch and sketch conditions for liars was significant, $F(1,60)=8.43, p=.005, d=0.74(0.21,1.24)$. Liars reported to have been more truthful in the Sketch-absent $(M=30.94, S D=19.90,95 \% \mathrm{CI}$ $[24.58,37.30])$ than in the Sketch-present condition $(M=17.67, S D=15.69,95 \%$ CI $[11.10$, 24.24]).

\section{Hypothesis Testing}

\section{Initial Free Recall}

A MANOVA with Veracity as the only factor was carried out with total details and complications as dependent variables. We hereby distinguished between details and complications about the 'Route to and from the location' and 'Experiences at the location' (descriptions of both the location and activities that took place there). The Sketch factor was not included in the design because the Sketch factor was introduced only after the Initial Free Recall. The analysis revealed a main effect for Veracity $F(4,117)=9.02, p<.001, \eta_{p}{ }^{2}=.24$. The univariate effects are presented in Table 1 (top of the Initial Free Recall part). Truth tellers reported more details and more complications, both about the Route to and from the location and about the experiences at the location. This supported Hypotheses 1 and $1 \mathrm{~b}$.

Table 1 about here

\section{Follow-up Recall Speech content}

A MANOVA utilizing a 2 (Veracity) X 2 (Sketch) between-subjects design was carried out with Total details and Complications as dependent variables. Since the Follow-up Recall focused on the location, the Route variables were no longer included. The analysis 
revealed a significant Veracity main effect, $F(2,117)=10.35, p<.001, \eta_{p}{ }^{2}=.15$, and a significant Sketch main effect, $F(2,117)=36.60, p<.001, \eta_{p}{ }^{2}=.39$. The Veracity x Sketch interaction effect was also significant, $F(2,117)=6.79, p=.002, \eta_{p}^{2}=.10$.

The univariate main effects for Veracity are presented in Table 1 (top of the Follow-up Recall part). The findings are similar to those found for the Initial Free Recall: Truth tellers provided more details and more complications about the experiences at the location than liars, supporting Hypotheses $1 \mathrm{a}$ and $1 \mathrm{~b}$.

The univariate main effects for Sketch are presented in Table 2. Sketching while narrating resulted in more details about the experiences at the location than just narrating, supporting Hypothesis 2a. The effect for complications was not significant, and thus Hypothesis $2 b$ was not supported.

Table 2 about here

At a univariate level, a significant Veracity x Sketch interaction effect occurred for total details, $F(1,118)=71.42, p<.001, \eta_{p}{ }^{2}=.38$. Simple tests analyses were carried out for the Sketch-absent and Sketch-present conditions separately and are presented in Table 3. The Sketch-absent condition did not result in significant differences between truth tellers and liars in reporting details about the location but the Sketch-present condition did: Truth tellers reported more details about the experiences at the location than liars. This supported Hypothesis 3a. The effect for complications was not significant, $F(1,118)=1.39, p=.241$, $\eta_{p}^{2}=.01$, and thus Hypothesis $3 \mathrm{~b}$ was not supported.

Table 3 about here

\section{Follow-up Recall Drawings}

A MANOVA was carried out with Veracity as factor and the total number of details in the exchange drawing and the concreteness of the exchange drawing as dependent variables. The multivariate effect was significant, $F(2,57)=3.97, p=.024, \eta_{p}{ }^{2}=.12$, but at a univariate 
level neither effect was significant, both $F^{\prime}$ 's $<1.42$, both $p$ 's $>.239$. Thus, Hypotheses 4 and 5 were not supported.

An ANOVA was carried out with Veracity as factor and the number of witnesses sketched as dependent variable. The effect was not significant, $F(1,58)=1.47, p=.23, d=$ $0.31(-.20, .82)$, with truth tellers $(M=1.70, S D=2.32,95 \% C I=[0.88,2.52])$ and liars $(M=$ $1.00, S D=2.15,95 \% C I=[0.18,1.82])$ sketching a similar number of witnesses. Hypothesis 6 was thus not supported.

Chi-square analyses were carried out to examine the relationship between Veracity and sketching the agent (yes or no) and perspective (shoulder camera or birds-eye). There was no association between Veracity and sketching the agent, $X^{2}(1, n=60)=.09, p=.766$, with $73 \%$ of truth tellers and $76.7 \%$ of liars sketching the agent. There was no association between Veracity and perspective taking in the drawing either, $X^{2}(1, n=60)=1.67, p=.196$, with $60 \%$ of truth tellers and $43.3 \%$ of liars using a birds-eye view. Hypotheses 7 and 8 were thus not supported.

\section{Exploratory Analyses}

\section{Initial Free Recall}

A MANOVA with Veracity as the only factor was carried out with the five types of descriptions listed in Table 1 (Initial Free Recall bottom part) and self-handicapping strategies as dependent variables. The Sketch factor was not included in the design because the Sketch factor was introduced only after the Initial Free Recall. The analysis revealed a main effect for Veracity $F(6,115)=12.98, p<.001, \eta_{p}{ }^{2}=.40$. Truth tellers provided more details than liars for each of the detail categories, except for descriptions of the package. The strongest effects were obtained for descriptions of what the interviewee thought and did and the verbal exchange with the agent. The findings for self-handicapping strategies were not significant, probably because they hardly occurred (see Table 1). 


\section{Follow-up Recall speech content}

A MANOVA utilizing a 2 (Veracity) X 2 (Sketch) between-subjects design was carried out with the five types of descriptions listed in Table 1 (Follow-up Recall bottom part) and self-handicapping strategies as dependent variables. Since the Follow-up Recall focused on the location, the variables about the route to and from the location were no longer included. The analysis revealed a significant Veracity main effect, $F(6,113)=4.76, p<.001$, $\eta_{p}{ }^{2}=.20$, and a significant Sketch main effect, $F(6,113)=12.86, p<.001, \eta_{p}{ }^{2}=.41$. The Veracity $\mathrm{x}$ Sketch interaction effect was also significant, $F(6,113)=3.42, p=.004, \eta_{p}{ }^{2}=.15$.

The univariate main effects for Veracity are presented in Table 1 (Follow-up Recall, bottom part). Truth tellers provided more details than liars for each of the detail categories, except for descriptions of the verbal exchange with the agent and of the package. Comparing these findings with the Initial Free Recall findings, a difference emerged for descriptions of the verbal exchange with the agent. Whilst a strong Veracity effect occurred in the Initial Free Recall, the difference between truth tellers and liars is no longer significant in the Follow-up Recall. The findings for self-handicapping strategies were again not significant.

The univariate main effects for Sketch are presented in Table 2. Sketching while narrating resulted in more detailed descriptions of the interior of the location and the agent and his/her actions. No other significant findings emerged.

At a univariate level, three significant Veracity x Sketch interaction effects occurred: for descriptions of the interior, $F(1,118)=11.04, p=.001, \eta_{p}{ }^{2}=.09$, agent, $F(1,118)=5.91$, $p=.017, \eta_{p}{ }^{2}=.05$ and verbal exchange with the agent, $F(1,118)=6.98, p=.009, \eta_{p}{ }^{2}=.06$. Simple tests analyses were carried out for the Sketch-absent and Sketch-present conditions separately and are presented in Table 3 . The Sketch-absent condition did not result in significant differences between truth tellers and liars but the Sketch-present condition did: 
Truth tellers gave more detailed descriptions of the interior of the location and the agent and his/her actions than liars.

\section{Follow-up Recall Drawings}

A MANOVA was carried out with Veracity as factor and the detail categories (interior and agent and exchange) as dependent variables. At a multivariate level the analysis was not significant, $F(2,57)=0.54, p=.637, \eta_{p}{ }^{2}=.02$, and neither were either of the univariate effects, both $F$ 's $<0.59$, both $p$ 's $>.447$. Chi-square analyses revealed that the associations between Veracity and sketching him/herself, $X^{2}(1, n=60)=0.66, p=.417$, the package, $X^{2}$ $(1, n=60)=1.67, p=.301$ or a verbal exchange, $X^{2}(1, n=60)=.00, p=1.00$, were not significant either.

A MANOVA was carried out utilising a 2 (Veracity) x 2 (Sketch) factorial design and the total number of details in the baseline drawing, the clarity of the baseline drawing and the ability to sketch as dependent variables. At a multivariate level a significant main effect for Sketch emerged, $F(3,116)=6.15, p=.001, \eta_{p}{ }^{2}=.14$, whereas the main effect for Veracity, $F(3,116)=0.24, p=.871, \eta_{p}{ }^{2}=.01$, and the Veracity $\mathrm{x}$ Sketch interaction effects, $F(3,116)=$ $0.96, p=.413, \eta_{p}{ }^{2}=.02$, were not significant. At a univariate level, the main Sketch effects for total details $F(1,118)=0.38, p=.539, d=.43(-.02, .86)$ and concreteness, $F(1,58)=$ $4.08, p=.046, d=.36(-.08, .80)$ were significant but the effect for sketching ability was not, $F(1,58)=0.13, p=.720, d=.07(-.29, .42)$. Those in the Sketch-present condition (who had made the experimental sketch earlier in the interview) included more details in the baseline drawing $(M=24.17, S D=12.60,95 \% \mathrm{CI}=[21.32,27.02]$ than those in the Sketch-absent condition (who did not make the experimental sketch earlier in the interview) $(M=19.18, S D$ $=9.54,95 \% \mathrm{CI}=[16.35,21.96]$. In addition, the baseline drawings in the Sketch-present condition $(M=4.83, S D=1.42,95 \% \mathrm{CI}=[4.48,5.19]$ were judged as more concrete than the baseline drawings in the Sketch-absent condition $(M=4.32, S D=1.35,95 \% \mathrm{CI}=[3.97$, 
4.67]. The absence of a Veracity main effect and Veracity x Sketch interaction effect shows that liars did not distinguish themselves from truth tellers in the baseline drawings.

\section{Strategies}

More liars $(n=50,80.6 \%)$ than truth tellers $(n=26,43.3 \%)$ reported to have thought about a strategy prior to the interview, $X^{2}(1, n=120)=18.07, p<.001$. More liars $(n=51$, $82.3 \%)$ than truth tellers $(n=23,38.3 \%)$ also reported to have executed a strategy during the interview, $X^{2}(1, n=120)=24.65, p<.001$.

The reported strategies are presented in Table 4. The most preferred strategy amongst truth tellers was to be detailed, both at the planning stage (pre-interview questionnaire) and the execution phase (post-interview questionnaire). For liars, the most preferred strategy was to stay close to the truth, followed by controlling visual nonverbal behaviours (e.g., gaze aversion, fidgeting).

Employing a "staying close to the truth" strategy means that liars could be largely truthful when reporting their experiences. To examine whether liars who did employ such a strategy provided more details than those who did not, we conducted a Spearman correlation between liars' strategy to stay close to the truth (Yes/No) and the number of details reported in the interview. A positive significant correlation occurred for the description of the route to and from the location in the Initial Free Recall $(r=.26, p=.044)$. The correlations for the total details of the experiences at the location were not significant for the Initial Free Recall ( $r$ $=-.01, p=.926)$ or Follow-up Recall $(r=.18, p=.161)$.

\section{Discussion}

The use of sketches had two positive effects on participants' speech. First, participants in the Sketch-present condition provided considerably more information than participants in the Sketch-absent condition $(d=1.39)$. Second, the Sketch instruction elicited total details as a cue to deceit: Truth tellers reported more details than liars, but only in the Sketch-present 
condition. In other words, the sketching tool was a particularly efficient interview tool because gathering information and being able to judge the truthfulness of that information are considered the two most important aims of investigative interviews (Brandon, 2011; Loftus, 2011). These two positive effects of sketching on reporting details replicates Vrij et al.

(2018a) findings, but go against Vrij et al. (2019) findings where no effects of sketching were found. We already gave a possible explanation for this. In Vrij et al. (2019), before introducing the Sketch manipulation, participants were asked to write down what they wanted to discuss in the interview. Through this instruction, participants may have committed themselves to what to report prior to the Sketch manipulation, which may have overshadowed the effect of the Sketch manipulation itself. This shows that it matters how a sketch is introduced in an interview to make it an efficient information-gathering and lie detection tool.

When we examined the subcategories of detail, we found that sketching resulted in more information about the location's interior and the agent and his/her actions. It also facilitated lie detection based on these two variables. Sketching also resulted in more information about what the interviewee did and thought at the location. This latter finding suggests that sketching (a visual format) encouraged participants to discuss not only visual details but also more action and conceptual details. Sketching did not affect the verbal exchange between participant and agent or description of the package. Inspection of the means showed that both subcategories were hardly recalled, suggesting a floor effect. The verbal exchange was actually short which did not give participants much opportunity to talk about it. Participants could have described the package in more detail than they did, but for unknown reasons chose not to do so.

Unlike what was found in Vrij et al. (2018a), the sketch instruction had no effect on reporting complications. We believe this is due to the low frequency of occurrence of complications during the interviews. Truth tellers reported on average only 0.90 
complications in the Follow-up Recall (the only phase in which the Sketch manipulation was implemented). Low frequency of occurrence of a variable makes it difficult for any manipulation to yield an effect.

Based on previous research we predicted five features in drawings to differentiate truth tellers from liars. Actually, not a single significant Veracity effect occurred. We do not wish to conclude that this means that drawing findings are difficult to replicate. Instead, we believe this has to do with the way sketching was introduced. In previous drawing studies, participants sketched without narrating. In that situation, the drawing becomes a stand-alone output. In the present study, sketching occurred in concurrence with narrating. In this situation, sketching probably became an aid to recall information. Although it served this function effectively (and also facilitated lie detection based on speech) it may have lost its function as a lie detection tool on its own. This again may show the importance of how sketching is introduced in interviews to function as an effective lie detection tool. Deception researchers have not yet began to investigate how to introduce a drawing in interviews to make it effective for lie detection purposes.

We explored whether liars would use their drawing skills as a self-handicapping strategy. That is, perhaps they deliberately would sketch poorly so that they would not give away cues in their drawings. We found no support for such a strategy. After the interview was completed liars and truth tellers were asked to sketch a scenario familiar to them (baseline drawing). We asked all participants to do this, including those in the Sketch-absent condition. We reasoned that if liars used a 'I cannot draw' self-handicapping strategy during the interview, they would continue this self-handicapping strategy when sketching the baseline drawing. This should result in the quality of the baseline drawings to be worse in the Sketchpresent than in the Sketch-absent condition, particularly for liars. This did not happen and we can only speculate why not. Perhaps liars did not think their drawings to be important to 
detect their deceit, which would be alignment with the reasoning introduced earlier that in the current experiment the sketch was used as a tool to facilitate recall and not as a stand-alone output.

The only difference we found in drawings was in the baseline drawings. The participants who had made a drawing during the interview (Sketch-present condition) produced a higher quality baseline drawing after the interview than participants who did not sketch during the interview (Sketch-absent condition). This may suggest that participants' sketching practice during the interview improved their performance in the baseline drawing. If practicing in sketching improves performance, investigators may consider to let interviewees practice their sketching skills before asking them to sketch during the interview. In terms of Veracity effects, truth tellers reported more details than liars, a consistent finding in deception research. In the Initial Free Recall, differences occurred for all subcategories of detail except describing the package. We cannot explain the absence of this effect. Although details about the package were rarely given in the Initial Free Recall, the lack of effect is not the result of a floor effect. Details about what the interviewee did and thought and about the agent and his/her actions were also rare in the Initial Free Recall, yet resulted in differences between truth tellers and liars. In the Follow-up Recall, the same Veracity effects occurred as in the Initial Free Recall, except for descriptions of the verbal exchange with the agent, which effect was no longer significant. The Veracity effect was substantial in the Initial Free Recall $(d=1.45)$ and truth tellers did not add much new information about the verbal exchange in the Follow-up Recall. It suggests that truth tellers provided all the relevant information in the Initial Free Recall. Liars did not provide much information about a verbal exchange in either phase.

The variable total details and many subcategories yielded strong Veracity effects in both the Initial Free Recall and Follow-up Recall ( $d$-scores ranged from medium to strong). 
This is worth noticing in relation to liars' strategies. Many of them reported to have stayed close to the truth during the interview. If liars change only a few details, detailed reports could be expected, perhaps as detailed as truth tellers' reports. This was not the case. In fact, there was no relationship between reporting to have stayed close to the truth and providing details about the experiences at the location in the Initial and Follow-Up Recalls. The correlation was significant for describing the route to and from the location in the Initial Free Recall but that correlation was still low $(r=.26)$. It suggests that liars provided less information than truth tellers even when they reported to have stayed close to the truth. This is in alignment with the findings of two other studies (Jundi, Vrij, Hope, Mann, \& Hillman, 2013; Vrij, Mann, Jundi, Hillman, \& Hope, 2014). In both studies, truth tellers and liars undertook the same mission. The difference between the two groups was the reason for carrying out these missions. Since in the interview participants were asked only about their activities during the mission and not about the reason for this mission, liars could have been entirely truthful. Yet, liars reported fewer details (Vrij, Mann, Jundi, Hillman, \& Hope, 2014) and fewer complications (Jundi, Vrij, Hope, Mann, \& Hillman, 2013) than truth tellers.

Complications emerged as a diagnostic cue to deceit in both the Initial Free Recall and Follow-up Recall, suggesting that Veracity effects also occur when interviewees recall short events. However, we expect such effects to be stronger and/or more stable when interviewees recall longer events. Self-handicapping strategies did not emerge as a cue to deceit, unlike in past research. We believe this to be due to the short time-span between the event and recalling the event. We expect self-handicapping strategies to yield stronger and/or more stable effects when interviewees report an event that happened a longer time ago. We could not examine common knowledge details because they did not seem to occur in the participants' recalls. We believe this is due to the out-of-ordinary nature of the experienced event. 
Previous research has shown the proportion of complications to be a more diagnostic indicator of veracity than the total details variable (Leal, Vrij, Deeb, \& Kamermans, 2019; Vrij et al., 2017, 2018a, b, 2019). The proportion of complications represents the proportion of truthfulness and is defined as: complications / (complications + common knowledge details + self-handicapping strategies). The reason why this proportion of complications variable has been found to be more diagnostic than the total details variable is that it takes the different strategies truth tellers and liars employ better into account than the total details variable. That is, both truth tellers and liars provide details, but they differ in the types of detail they provide. In the present experiment, however, the proportion of complication score was not calculated, because self-handicapping strategies did not differentiate truth tellers from liars and common knowledge details did not occur. Such a proportion score may perhaps be useful in specific scenarios: When interviewees discuss an event of a certain duration that is not entirely out of the ordinary and did not happen just before the interview took place (Vrij et al., 2018b). Future research could examine this.

Future research could also examine the efficacy of the use of drawings as a function of the length of the time period someone describes. In the present experiment, the interviewees were asked to focus on a specific moment in time (the exchange with the agent) and asked to narrate and sketch what they experienced at that specific time. This is a different instruction from asking to narrate and sketch what they experienced during the entire mission. In that situation an interviewee will perhaps produce several sketches each representing a specific scene. On the one hand, perhaps interviewees give more details in speech and sketch when making just one sketch than when making multiple sketches due to a fatigue or boredom effect when making multiple sketches and discussing multiple events. On the other hand, perhaps interviewees report more details in their speech and sketches in a multiple sketch 
scenario because over time they become more comfortable with sketching. Future research could examine the efficacy of drawings when interviewees discuss a longer period of time.

Applying our findings to real life situations where veracity decisions need to be made in individual cases is challenging. Veracity assessment methods would be most effective if truth tellers and liars display truly different response patterns. For example, if in their statements truth tellers always include more complications than common knowledge details or self-handicapping strategies and liars always include more common knowledge details or selfhandicapping strategies than complications (e.g. Vrij, 2016; Nahari \& Vrij, 2015). In that case a clear cut-off score can be established, but this does not happen in real life. All that can be concluded is that truth tellers typically obtain a higher proportion of complications than liars. Polygraph examinations use cut-off scores, which may explain why such examinations are so popular amongst practitioners. Not a single veracity assessment tool (or nonverbal lie detection method) employs cut-off scores and developing those should be the focus of deception researchers examining speech content. Recent research into 'verbal baselining' is perhaps a step in the right direction (Palena, Caso, \& Vrij, 2019; Schemmel, Maier, \& Volbert, 2020; Verigin, Meijer, Vrij, \& Zauzig, 2020).

\section{Conclusion}

The instruction to sketch while narrating increased the amount of information provided and facilitated lie detection. Truth tellers and liars did not differ in their drawings, perhaps because sketching was introduced as a tool that facilitated verbal recall and the sketch output was not considered a stand-alone output.

\footnotetext{
${ }^{1}$ We conducted an a priori power analysis via $G^{*}$ Power software. We used the effect size found in the existing deception literature that involves sketching while narrating (Vrij et al., 2018a). As we were interested in the proportion of complications score, we used the effect size for this variable $(d=0.65)$ to determine power. Based on this effect size and on an $n=30$ per cell—which is reasonable to achieve at least $80 \%$ power (Cohen, 1988) — the analysis showed that we can achieve $94 \%$ power for the current study.
} 


\section{Acknowledgements}

This work was funded by the Centre for Research and Evidence on Security Threats (ESRC Award: ES/N009614/1)

\section{Availability of data}

The data that support the findings of this study are available from the corresponding author upon reasonable request. 


\section{References}

Amado, B. G., Arce, R., Fariña, F., \& Vilarino, M. (2016). Criteria-Based Content Analysis (CBCA) reality criteria in adults: A meta-analytic review. International Journalistepof Clinical and Health Psychology, 16, 201-210. Doi: 10.1016/j.ijchp.2016.01.002

Barlow, C. M., Jolley, R. P., \& Hallam. J. (2010). Drawing as memory aids: Optimising the drawing method to facilitate young children's recall. Applied Cognitive Psychology, 25, 480-487. Doi: 10.1002/acp1716

Butler, S., Gross, J., \& Hayne, H. (1995). The effect of drawing on memory performance in young children. Developmental Psychology, 31, 597-608. Doi: 10.1037/00121649.31.4.597

Brandon, S. (2011). Impacts of psychological science on national security agencies post-9/11. American Psychologist, 66, 495-506. Doi: 10.1037/a0024818

* Calderon, S., Mac Giolla, E., Ask, K., \& Granhag, P. A. (2018). Drawing what lies ahead: False intentions are more abstractly depicted than true intentions. Applied Cognitive Psychology, 32, 518-522. Doi: 10.1002/acp.3422

Cohen, J. (1988). Statistical power analysis for the behavioral sciences (2nd ed.). Hillsdale, NJ: Erlbaum

Colwell, K., Hiscock-Anisman, C., Memon, A., Woods, D., \& Michlik, P. M. (2006). Strategies of impression management among deceivers and truth tellers: How liars attempt to convince. Amercian Journal of Forensic Psychology, 24, 31-38.

Dando, C., Wilcock, R., \& Milne, R. (2009). The Cognitive Interview: The efficacy of a modified mental reinstatement of context procedure for frontline police investigators. Applied Cognitive Psychology, 23, 138-147. Doi: 10.1002/acp.1451 
* Deeb, H, Granhag, P. A., Vrij, A., Strömwall, L., Hope, L., \& Mann, S. (2018).

Visuospatial counter-interrogation strategies by liars familiar with the alibi setting. Applied Cognitive Psychology, 32, 105-116. Doi: 10.1002/acp.3383

DePaulo, B. M., Lindsay, J. L., Malone, B. E., Muhlenbruck, L., Charlton, K., \& Cooper, H. (2003). Cues to deception. Psychological Bulletin, 129, 74-118. Doi: 10.1037/00332909.129.1.74

DePaulo, B. M., \& Morris, W. L. (2004). Discerning lies from truths: Behavioural cues to deception and the indirect pathway of intuition. In P. A. Granhag \& L. A. Strömwall (Eds.), Deception detection in forensic contexts (pp. 15-40). Cambridge, England: Cambridge University Press.

Fisher, R. P., \& Geiselman, R. E. (1992). Memory enhancing techniques for investigative interviewing: The cognitive interview. Springfield, Il: Charles C. Thomas.

Hartwig, M., Granhag, P. A., \& Strömwall, L. (2007). Guilty and innocent suspects’ strategies during interrogations. Psychology, Crime, \& Law, 13, 213-227. Doi: $10.1080 / 10683160600750264$.

Hartwig, M., Granhag, P. A., Strömwall, L, \& Doering, N. (2010). Impression and information management: On the strategic self-regulation of innocent and guilty suspects. The Open Criminology Journal, 3, 10-16. Doi: $10.2174 / 1874917801003010010$.

Jundi, S., Vrij, A., Hope, L., Mann, S., \& Hillman, J. (2013). Establishing evidence through undercover and collective intelligence interviewing. Psychology, Public Policy, \& Law, 19, 297-306. Doi: 10.1037/a0033571

Köhnken, G. (2004). Statement Validity Analysis and the 'detection of the truth'. In P. A. Granhag \& L. A. Strömwall (Eds.), Deception detection in forensic contexts (pp. 41-63). Cambridge, England: Cambridge University Press. 
Leins, D., Fisher, R. P., Pludwinsky, L., Robertson, B., \& Mueller, D.H. (2014). Interview protocols to facilitate human intelligence sources' recollections of meetings. Applied Cognitive Psychology, 28, 926-935. Doi: 10.1002/acp.3041

Leins, D., Fisher, R. P., \& Ross, S. J. (2013). Exploring liars' strategies for creating deceptive reports. Legal and Criminological Psychology, 18, 141-151. Doi: 10.1111/j.20448333.2011.02041.x

* Leins, D., Fisher, R., \& Vrij, A. (2012). Drawing on liars' lack of cognitive flexibility: Detecting deception through varying report modes. Applied Cognitive Psychology, 26, 601-607. Doi: 10.1002/acp.2837.

* Leins, D., Fisher, R. P., Vrij, A., Leal, S., \& Mann, S. (2011). Using sketch-drawing to induce inconsistency in liars. Legal and Criminological Psychology, 16, 253-265. Doi: $10.1348 / 135532510 X 501775$.

Leal, S., Vrij, A., Deeb, H., \& Kamermans, K. (2019). Encouraging interviewees to say more and deception: The Ghostwriter method. Legal and Criminological Psychology. Doi:10.1111/lcrp.12152

Loftus, E. F. (2011). Intelligence gathering post-9/11. American Psychologist, 66, 532-541. Doi: $10.1037 / \mathrm{a} 0024614$

Mac Giolla, E., Granhag, P. A., \& Vernham, Z. (2017). Drawing-based deception detection techniques: A state-of-the-art review. Crime Psychology Review, 2017, 3, 23-38. Doi: 10.1080/237440062017.1393986.

Mattison, M. C. L., Dando, C. J., \& Ormerod, T. C. (2015). Sketching to remember: Episodic free recall task support for child witnesses and victims with autism spectrum disorder. Journal of Autism and Developmental Disorders, 45, 1751-1765. Doi: DOI $10.1007 / \mathrm{s} 10803-014-2335-\mathrm{Z}$ 
Milne, R., \& Bull, R. (1999). Investigative interviewing: Psychology and practice. Chichester, England: John Wiley \& Sons.

Nahari, G., \& Vrij, A. (2015). Systematic errors (biases) in applying verbal lie detection tools: richness in detail as a test case. Crime Psychology Review, 1, 98-107. Doi: $10.1080 / 23744006.2016 .1158509$

Nahari, G., Vrij, A., \& Fisher, R. P. (2014). Exploiting liars' verbal strategies by examining the verifiability of details. Legal and Criminological Psychology, 19, 227-239. Doi: $10.1111 / \mathrm{j} .2044-8333.2012 .02069 . \mathrm{x}$

Palena, N., Caso, L., \& Vrij, A. (2019). Detecting lies via a theme-selection strategy. Frontiers in Psychology, section Forensic and Legal Psychology. Doi: 10.3389/fpsyg.2018.02775

* Roos af Hjelmsäter, E., Öhman, L., Granhag, P. A., \& Vrij, A. (2014). Mapping deception in adolescents: Eliciting cues to deceit through an unanticipated spatial drawing task. Legal and Criminological Psychology, 19, 179-188. Doi: 10.1111/j.20448333.2012.02068.x

Ruby, C. L., \& Brigham, J. C. (1998). Can Criteria-Based Content Analysis distinguish between true and false statements of African-American speakers? Law and Human Behavior, 22, 369-388. Doi: 10.1023/A:1025766825429

Schemmel, J., Maier, B. G., \& Volbert, R. (2020). Verbal baselining: Within-subjects consistency of CBCA scores across different truthful and fabricated accounts. The European Journal of Psychology Applied to Legal Context, 12, 35-42. Doi: 10.5093/ejpalc2020a4.

Sporer, S. L. (2016). Deception and cognitive load: Expanding our horizon with a working memory model. Frontiers in Psychology: Hypothesis and Theory, 7, article 420. Doi: 10.3389/fpsyg.2016.00420. 
* Van Veldhuizen, T. S., Horselenberg, R., Stel, M., Landström, S., Granhag, P. A., \& van Koppen, P. J. (2017). The provenance of émigrés: the validity of measuring knowledge of places. Psychology, Crime, \& Law, 23, 553-574. Doi:

10.1080/1068316X.2017.1284219

Verigin, B., Meijer, E. H., Vrij, A., \& Zauzig, L. (2020). The interaction of truthful and deceptive information. Psychology, Crime, \& Law. Doi:

10.1080/1068316X.2019.1669596

Vrij, A. (2008). Detecting lies and deceit: Pitfalls and opportunities, second edition. Chichester: John Wiley and Sons.

Vrij, A. (2016). Baselining as a lie detection method. Applied Cognitive Psychology, 30, 1112-1119. Doi: 10.1002/acp.3288

Vrij, A., \& Granhag, P. A. (2012). Eliciting cues to deception and truth: What matters are the questions asked. Journal of Applied Research in Memory and Cognition, 1, 110-117. Doi: $10.1016 /$ j.jarmac.2012.02.

* Vrij, A., Leal, S., Fisher, R. P., Mann, S., Dalton, G. Jo, E., Shaboltas, A., Khaleeva, M., Granskaya, J., \& Houston, K. (2018a). Sketching as a technique to elicit information and cues to deceit in interpreter-based interviews. Journal of Applied Research in Memory and Cognition, 7, 303-313. Doi: 10.1016/j.jrarmac.2017.11.001

Vrij, A., Leal, S., Fisher, R. P., Mann, S., Deeb, H., Jo, E., Castro Campos, C., \& Hamzeh, S. (2020). The efficacy of using countermeasures in a Model Statement interview. European Journal of Psychology Applied to Legal Context, 12, 23-34. Doi: 10.5093/ejpalc2020a3

* Vrij, A., Leal, S., Fisher, R. P., Mann, S., Jo, E., Shaboltas, A., Khaleeva, M., Granskaya, J., \& Houston, K. (2019). Eliciting information and cues to deceit through sketching in interpreter-based interviews. Applied Cognitive Psychology. Doi: 10.1002/acp.3566 
* Vrij, A., Leal, S., Granhag, P. A., Mann, S., Fisher, R. P., Hillman, J., \& Sperry, K. (2009). Outsmarting the liars: The benefit of asking unanticipated questions. Law and Human Behavior, 33, 159-166. Doi: 10.1007/s10979-008-9143-y.

Vrij, A., Leal, S., Jupe, L., \& Harvey, A. (2018b). Within-subjects verbal lie detection measures: A comparison between total detail and proportion of complications. Legal and Criminological Psychology. Doi:10.1111/lcrp.12126

Vrij, A., Leal, S., Mann, S., Dalton, G. Jo, E., Shaboltas, A., Khaleeva, M., Granskaya, J., \& Houston, K. (2017). Using the Model Statement to elicit information and cues to deceit in interpreter-based interviews. Acta Psychologica, 177, 44-53. Doi: 10.1016/j.actpsy.2017.04.011

Vrij, A., Leal, S., Mann, S., \& Fisher, R. (2012). Imposing cognitive load to elicit cues to deceit: Inducing the reverse order technique naturally. Psychology, Crime, \& Law, 18, 579-594. Doi: 10.1080/1068316X2010.515987

* Vrij, A., Leal, S., Mann, S., Warmelink, L., Granhag, P. A., \& Fisher, R. P. (2010). Drawings as an innovative and successful lie detection tool. Applied Cognitive Psychology, 4, 587-594. DOI: 10.1002/acp/1627

Vrij, A., Mann, S., Jundi, S., Hillman, J. \& Hope, L. (2014). Detection of concealment in an information-gathering interview. Applied Cognitive Psychology, 28, 860-866, Doi: 10.1002/acp.305.

*Vrij, A., Mann, S., Leal, S., \& Fisher, R. (2012). Is anyone there? Drawings as a tool to detect deception in occupations interviews. Psychology, Crime, \& Law, 18, 377-388. Doi: 10.1080/1068316X.2010.498422

Vrij, A., Mann, S., Leal, S., \& Granhag, P. A. (2010). Getting into the minds of pairs of liars and truth tellers: An examination of their strategies. The Open Criminology Journal, 3, 17-22. Doi: 10.2174/1874917801003010017 
Wesson, M., \& Salmon, K. (2001). Drawing and showing: Helping children to report emotionally laden events. Applied Cognitive Psychology, 15, 301-319. Doi: 10.1002/acp.706) 
Table 1 Statistical Results as a Function of Veracity

\begin{tabular}{|c|c|c|c|c|c|c|c|c|}
\hline & \multicolumn{2}{|c|}{ Truth } & \multicolumn{2}{|c|}{ Lie } & \multirow{2}{*}{$\boldsymbol{F}$} & \multirow{2}{*}{$p$} & \multicolumn{2}{|c|}{ Cohen's $d$} \\
\hline & $M(S D)$ & $95 \%$ CI & $M(S D)$ & $95 \% \mathrm{CI}$ & & & $d$ & $95 \% \mathrm{CI}$ \\
\hline \multicolumn{9}{|l|}{ Initial Free Recall } \\
\hline Description of route to and from the location & $20.47(19.59)$ & $16.79,24.14$ & $07.29(05.96)$ & $03.68,10.91$ & 25.61 & $<.001$ & 0.92 & $0.53,1.28$ \\
\hline Total details of experiences at the location & $13.62(7.64)$ & $11.88,15.35$ & $07.81(05.82)$ & $6.10,9.51$ & 22.39 & $<.001$ & 0.86 & $0.47,1.21$ \\
\hline Complications en route to and from location & $01.05(01.73)$ & $00.72,01.38$ & $00.29(00.64)$ & $-0.04,00.62$ & 10.47 & .002 & 0.59 & $0.22,0.94$ \\
\hline Complications at the location & $00.78(01.47)$ & $00.51,01.06$ & $00.10(00.35)$ & $-0.17,00.36$ & 12.72 & .001 & 0.64 & $0.27,1.00$ \\
\hline Description of location interior & $01.58(01.82)$ & $01.20,01.97$ & $00.71(01.14)$ & $00.33,01.09$ & 10.22 & .002 & 0.58 & $0.20,0.93$ \\
\hline Description of agent and his/her actions & $06.17(03.97)$ & $05.23,07.11$ & $03.95(03.38)$ & $03.04,04.88$ & 11.03 & .001 & 0.60 & $0.12,0.96$ \\
\hline $\begin{array}{l}\text { Description of what interviewee thought } \\
\text { and did at the location }\end{array}$ & $02.38(02.43)$ & $01.91,02.85$ & $00.68(00.97)$ & 00.22 .01 .14 & 26.25 & $<.001$ & 0.92 & $0.54,1.28$ \\
\hline Description of verbal exchange with the agent & $02.12(01.28)$ & $01.83,02.40$ & $00.60(00.91)$ & $00.32,00.88$ & 57.46 & $<.001$ & 1.45 & $1.03,1.83$ \\
\hline Description of the package & $01.37(00.94)$ & $01.01,01.73$ & $01.87(01.76)$ & $01.52,02.23$ & 03.86 & .052 & 0.36 & $-0.01,0.71$ \\
\hline $\begin{array}{l}\text { Self-handicapping strategies en route } \\
\text { to and from location }\end{array}$ & $00.00(00.00)$ & $-0.02,00.02$ & $00.02(00.13)$ & $-0.01,00.04$ & 00.97 & .327 & 0.22 & $-0.14,0.57$ \\
\hline Self-handicapping strategies at the location & $00.00(00.00)$ & $00.00,00.00$ & $00.00(00.00)$ & $00.00,00.00$ & . & . & & . \\
\hline Follow-up Recall & & & & & & & & \\
\hline Total details of experiences at the location & $24.98(19.32)$ & $21.94,28.03$ & $15.97(10.27)$ & $13.14,19.14$ & 16.78 & $<.001$ & 0.59 & $0.21,0.94$ \\
\hline
\end{tabular}


Complications at the location

Description of location interior

Description of agent and his/her actions

Description of what interviewee thought and did at the location

Description of verbal exchange with the agent

Description of the package

Self-handicapping strategies at the location
$00.90(01.24) \quad 00.62,01.18$

$14.78(15.06) \quad 12.39,17.17$

$06.72(05.13) \quad 05.65,07.78$

$02.40(02.31) \quad 01.02,02.88$

$00.32(00.65) \quad 00.15,00.49$

$00.77(02.48) \quad 00.30,01.24$

$00.15(00.44) \quad 00.03,00.27$
$00.47(00.92)$

$00.19,00.74$

04.82

.030

$0.39 \quad 0.03,0.75$

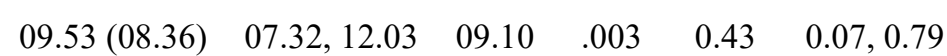

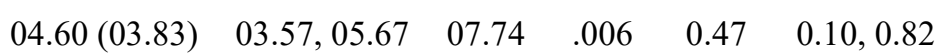

$01.11(01.33) \quad 00.64,01.59 \quad 14.13 \quad<.001 \quad 0.69 \quad 0.31,1.04$

$00.32(00.72) \quad 00.16,00.50 \quad 00.01 \quad .925 \quad 0.00 \quad-0.35,0.35$

$00.40(00.80) \quad-0.06,00.87 \quad 01.19 \quad 278 \quad 0.20 \quad-0.16,0.55$

$00.27(00.48) \quad 00.16,00.39 \quad 02.17 \quad .144 \quad 0.26 \quad-0.10,0.61$ 
Table 2 Statistical Results as a Function of Sketch

\begin{tabular}{|c|c|c|c|c|c|c|c|c|}
\hline & \multicolumn{2}{|c|}{ Sketch-absent } & \multicolumn{2}{|c|}{ Sketch-present } & \multirow{2}{*}{$F$} & \multirow{2}{*}{$p$} & \multicolumn{2}{|c|}{ Cohen's $d$} \\
\hline & $M(S D)$ & $95 \%$ CI & $M(S D)$ & $95 \%$ CI & & & $d$ & $95 \% \mathrm{CI}$ \\
\hline \multicolumn{9}{|l|}{ Follow-up Recall } \\
\hline Total details of experiences at the location & $11.42(06.52)$ & $8.44,14.44$ & $29.68(17.55)$ & $26.64,32.73$ & 71.42 & $<.001$ & 1.39 & $0.97,1.76$ \\
\hline Complications at the location & $00.79(01.10)$ & $00.53,01.08$ & $00.57(01.11)$ & $00.29,00.85$ & 01.42 & .237 & 0.20 & $-0.16,0.55$ \\
\hline Description of location interior & $04.97(04.33)$ & $2.61,7.31$ & $19.50(13.59)$ & $17.11,21.89$ & 73.74 & $<.001$ & 1.45 & $1.03,1.83$ \\
\hline Description of agent and his/her actions & $04.10(07.23)$ & $03.05,05.15$ & $07.23(04.98)$ & $06.20,08.30$ & 17.24 & $<.001$ & 0.50 & $0.13,0.86$ \\
\hline $\begin{array}{l}\text { Description of what interviewee thoughts } \\
\text { and did at the location }\end{array}$ & $01.60(01.82)$ & $01.14,02.09$ & $01.90(02.13)$ & $01.42,02.38$ & 00.69 & .407 & 0.15 & $-0.21,0.50$ \\
\hline Description of verbal exchange with the agent & $00.31(00.64)$ & $00.14,00.48$ & $00.33(00.73)$ & $00.16,00.51$ & 00.03 & .858 & 0.03 & $-0.33,0.38$ \\
\hline Description of the package & $00.45(00.76)$ & $-0.01,00.92$ & $00.72(02.50)$ & $00.25,01.19$ & 00.62 & .432 & 0.15 & $-0.21, .50$ \\
\hline Self-handicapping strategies at the location & $00.19(00.43)$ & $00.07,00.31$ & $00.23(00.50)$ & $00.11,00.35$ & 00.24 & .625 & 0.22 & $-0.14,0.57$ \\
\hline
\end{tabular}


Table 3 Statistical Results as a Function of Veracity and Sketch

\begin{tabular}{|c|c|c|c|c|c|c|c|c|}
\hline & \multicolumn{2}{|c|}{ Truth } & \multicolumn{2}{|c|}{ Lie } & \multirow{2}{*}{$\boldsymbol{F}$} & \multirow{2}{*}{$p$} & \multicolumn{2}{|c|}{ Cohen's $d$} \\
\hline & $M(S D)$ & $95 \% \mathrm{CI}$ & $M(S D)$ & $95 \% \mathrm{CI}$ & & & $d$ & $95 \% \mathrm{CI}$ \\
\hline \multicolumn{9}{|l|}{ Follow-up Recall } \\
\hline Sketch-absent: Total details of experiences at the location & $12.13(06.59)$ & $9.75,14.52$ & $10.75(06.48)$ & $8.44,13.06$ & 00.69 & .408 & 0.21 & $-0.29,0.71$ \\
\hline Sketch-present: Total details of experiences at the location & $37.83(19.35)$ & $32.12,43.55$ & $21.53(10.73)$ & $15.82,27.25$ & 16.29 & $<.001$ & 1.04 & $0.49,1.56$ \\
\hline Sketch-absent: Description of location interior & $04.70(04.41)$ & $03.11,06.29$ & $05.22(04.32)$ & $03.68,06.76$ & 00.22 & .642 & 0.12 & $-0.38,0.62$ \\
\hline Sketch-present: Description of location interior & $24.86(15.21)$ & $20.27,29.46$ & $14.13(09.21)$ & $09.54,18.73$ & 10.93 & .002 & 0.85 & $0.31,1.37$ \\
\hline Sketch-absent: Description of agent and his/her actions & $04.23(03.06)$ & $02.89,05.58$ & $03.97(04.19)$ & $02.67,05.27$ & 00.08 & .778 & 0.07 & $-0.43,0.57$ \\
\hline Sketch-present: Description of agent and his/her actions & $09.20(05.60)$ & $07.52,10.89$ & $05.27(03.34)$ & $03.58,06.95$ & 10.92 & .002 & 0.85 & $0.31,1.37$ \\
\hline Sketch-absent: Description of verbal exchange with the agent & $00.47(00.78)$ & $00.24,00.70$ & $00.16(00.45)$ & $-0.07,00.38$ & 03.78 & .057 & 0.49 & $-0.02,0.99$ \\
\hline Sketch-absent: Description of verbal exchange with the agent & $00.17(00.46)$ & $-0.10,00.43$ & $00.50(00.90)$ & $00.24,00.76$ & 03.26 & .076 & 0.46 & $-0.06,0.97$ \\
\hline
\end{tabular}


Table 4. Self-reported Strategies

\begin{tabular}{|l|c|c|c|c|c|}
\hline & \multicolumn{2}{|c|}{ Truth tellers } & & \multicolumn{2}{c|}{ Liars } \\
\hline & Pre & Post & & Pre & Post \\
\hline Stay close to the truth & $1.7 \%$ & $0 \%$ & & $41.9 \%$ & $40.3 \%$ \\
\hline Keep it simple & $1.7 \%$ & $1.7 \%$ & & $9.7 \%$ & $11.3 \%$ \\
\hline Be detailed & $40 \%$ & $33.3 \%$ & & $16.1 \%$ & $9.7 \%$ \\
\hline $\begin{array}{l}\text { Countermeasure } \\
\text { technique }\end{array}$ & $3.3 \%$ & $0 \%$ & & $6.5 \%$ & $0 \%$ \\
\hline $\begin{array}{l}\text { Countermeasure } \\
\text { interviewer }\end{array}$ & $3.3 \%$ & $5 \%$ & & $6.5 \%$ & $8.1 \%$ \\
\hline $\begin{array}{l}\text { Nonverbal behaviour: } \\
\text { Visual }\end{array}$ & $21.7 \%$ & $13.3 \%$ & & $24.2 \%$ & $19.4 \%$ \\
\hline $\begin{array}{l}\text { Nonverbal behaviour: } \\
\text { Vocal }\end{array}$ & $8.3 \%$ & $1.7 \%$ & & $14.5 \%$ & $8.1 \%$ \\
\hline
\end{tabular}


Appendix 1. Self-Reported Strategies in the Pre-Interview Questionnaire

\begin{tabular}{|l|l|}
\hline Description & Type of strategy \\
\hline $\begin{array}{l}\text { Keep in familiar information, e.g. location, } \\
\text { agent, object, story }\end{array}$ & Stay close to the truth \\
\hline $\begin{array}{l}\text { Change key detail change in agent e.g. } \\
\text { gender }\end{array}$ & Stay close to the truth \\
\hline Keeping it brief/quick/avoid waffle/ simple & Keep it simple \\
\hline Give detail & Give detail \\
\hline Avoid giving too much detail & Keep it simple \\
\hline $\begin{array}{l}\text { Include spatial details/verifiable/self- } \\
\text { handicapping (excuses) }\end{array}$ & Countermeasures technique \\
\hline Base lie on truth/tell some truth & Stay close to the truth \\
\hline Avoid outright fabrications/keep lie small & Stay close to the truth \\
\hline $\begin{array}{l}\text { Strategy mentioned involves object in some } \\
\text { way }\end{array}$ & Stay close to the truth \\
\hline Visualise/imagine the lie & Countermeasures interviewer \\
\hline Keep or avoid eye contact & Nonverbal behaviour: visual \\
\hline Avoid speech errors/hesitation (or hesitate) & Nonverbal behaviour: vocal \\
\hline Tell truth/it all/be honest/as remembered & Speech give detail \\
\hline Control body language/hands/breath & Nonverbal behaviour: visual \\
\hline $\begin{array}{l}\text { Look/ be relaxed/ confident/calm/not } \\
\text { nervous }\end{array}$ & Nonverbal behaviour: visual \\
\hline $\begin{array}{l}\text { Look as though thinking/remembering } \\
\text { what happened }\end{array}$ & Countermeasures interviewer \\
\hline Smile & Countermeasures interviewer \\
\hline $\begin{array}{l}\text { Control voice/sound a certain way } \\
\text { confident) }\end{array}$ & Nonverbal behaviour: vocal \\
\hline Befriend/confuse/focus on interviewer & Countermeasures interviewer \\
\hline
\end{tabular}


Appendix 2. Self-Reported Strategies in the Post-Interview Questionnaire

\begin{tabular}{|l|l|}
\hline More info & Strategy \\
\hline $\begin{array}{l}\text { Keep in familiar information, e.g. location, } \\
\text { agent, object, story }\end{array}$ & Stay close to the truth \\
\hline Give detail/be detailed/extra detail & Give detail \\
\hline Include truth/base on truth & Stay close to the truth \\
\hline Smiled / laughed & Countermeasures interviewer \\
\hline Focused on interviewer & Countermeasures interviewer \\
\hline Maintaining eye contact & Nonverbal behaviour: visual \\
\hline Avoid giving detail & Keep it simple \\
\hline Specifics relating to agent & Stay close to the truth \\
\hline & Nonverbal behaviour: visual \\
\hline Relax/calm/confident & Nonverbal behaviour: visual \\
\hline Small lie about small details & Stay close to the truth \\
\hline Keep it short/brief/quick/ don't say too much & Stay keep it simple \\
\hline $\begin{array}{l}\text { Told truth/tell it all/as remembered (differs to } \\
\text { include truth above) }\end{array}$ & Give detail \\
\hline Sound confident/control voice/tone/speech & Nonverbal behaviour: vocal \\
\hline Keep the truth in & Stay close to the truth \\
\hline
\end{tabular}

